\title{
O RETRATO DA ESCOLA SEGUNDO O OLHAR DE JOVENS E ADULTOS COM DEFICIÊNCIA INTELECTUAL MATRICULADOS NA EJA REGULAR
}

\author{
THE SCHOOL PORTRAIT ACCORDING TO INTELLECTUAL DISABILITY YOUNG \\ AND ADULT VIEW ENROLLED IN EJA (YOUNG AND ADULT EDUCATION)
}

\author{
Patricia Oliveira ${ }^{1}$ \\ Juliane Aparecida de Paula Perez Campos ${ }^{2}$
}

\begin{abstract}
Resumo
A crescente presença de jovens e adultos com deficiência na EJA tem se apresentado como um novo campo de estudos repleto de lacunas de conhecimento. O objetivo desta pesquisa foi descrever como estes alunos retratam a escola e o seu processo de escolarização. Para a coleta de dados foi solicitado a três alunos com deficiência intelectual que fotografassem os espaços escolares. Posteriormente foi realizada uma entrevista individual na qual deveriam escolher 10 imagens, descrevê-las e apontar os motivos de sua escolha. As entrevistas foram registradas em áudio, transcritas e analisadas. A análise apontou para três categorias: Acolhimento, Relação Professor e Aluno, e Atendimento às Necessidades Educacionais. Os dados indicaram que os participantes se sentem acolhidos pela EJA e possuem boas perspectivas sobre sua escolarização, mas ainda há problemas na relação entre professor e aluno e no oferecimento de um atendimento que atenda às expectativas.
\end{abstract}

Palavras-chave: Educação de Jovens e Adultos. Deficiência Intelectual. Escola.

\begin{abstract}
The growing presenceof young and adults with disability in EJA have been presented as a new field of studies full of knowledge gaps. The goal of this study was to describe how these students see the school and its schooling process. To collect the data three students with mental retardation were requestedto take pictures of the school. After that, there was an individual interview in which the participants should choose 10 images, describe them and point out the reasons of their choices. The interviews were registered in audio, transcribed and analyzed. The analyzesshowed three categories: reception, relation between teacher and student, and educational needs service. The data indicates that the participants feel accepted in

\footnotetext{
${ }^{1}$ Doutora e mestre em Educação Especial pela Universidade Federal de São Carlos, Especialista em Educação Especial pelo Centro Universitário Central Paulista - UNICEP. Docente dos cursos de Psicopedagogia e Neuropedagogia e Psicanálise do Centro Universitário Central Paulista (UNICEP) e do curso de Psicopedagogia do Centro Universitário Fundação Hermínio Ometto (UNIARARAS). E-mail: patriciaoliveira.eduesp@gmail.com

${ }^{2}$ Doutora em Educação Especial pela Universidade Federal de São Carlos, Mestrado em Educação Especial pela Universidade Federal de São Carlos, Graduação em Psicologia pela Universidade Federal de Uberlândia, e Graduação em Pedagogia pelo Centro Universitário Claretiano. Professor adjunto, nível III, do Departamento de Psicologia da Universidade Federal de São Carlos. E-mail: jappcampos@gmail.com
} 
EJA and have good perspectives about their schooling, but there are still problems in the relation between teachers and students as well as in the offer of a type of service that respond to their expectation

Keywords: Young and adult education. Intellectual disability. School.

\section{INTRODUÇÃO}

A inclusão de jovens e adultos com deficiência no sistema regular de ensino tem se apresentado como um tema de pesquisa bastante relevante e oportuno, pois os jovens e adultos com deficiência constituem hoje uma ampla parcela da população analfabeta no mundo devido à falta de oportunidades para a sua escolarização, deixando-os à margem dos serviços educacionais, sociais, de saúde e de reabilitação (FERREIRA, 2009; SIEMS, 2012; SÃO PAULO, 2012).

As primeiras pesquisas que vem emergindo deste novo campo já nos trazem dados bastante pertinentes para o conhecimento deste e da maneira como ele vem se constituindo, além dos movimentos e ações que tem sido realizada, em busca do atendimento desta parcela da população.

Em relação às matrículas destes alunos, Ferreira (2009), Campos; Duarte (2011), Fernandes (2011) e Gonçalves (2012) apontaram que, mesmo com um quadro significativo de matrículas de jovens e adultos com deficiências em instituições particulares, o número de matrículas em instituições públicas que oferecem EJA também avançou consideravelmente. Entretanto, os estados e municípios vêm permitindo a abertura de classes e turmas especiais para o atendimento dos alunos que têm migrado das instituições especiais para o ensino regular comum, e para aqueles que não tiveram acesso à escolarização em virtude de sua deficiência.

Sobre o atendimento pedagógico oferecido a esses estudantes, Carvalho (2006), Fonseca (2007), Maffezoli e Góes (2010), e Fernandes (2011) relataram que não há nenhum tratamento pedagógico aparente e preocupado com as especificidades destes alunos: o trabalho pedagógico tem se apresentado de forma mecânica e baseada na repetição, com atividades infantilizadas, e sem apresentar uma organização adequada às necessidades educacionais dessa clientela. Além disso, o gerenciamento do tempo também tem se mostrado bastante inadequado, abrindo grandes lacunas no processo de ensino e aprendizagem (FONSECA, 2007; FERNANDES, 2011). 
Essas características apontadas sobre o atendimento pedagógico oferecido, de acordo com as pesquisadoras, reproduzem o conceito subjacente de que os indivíduos com deficiência são incapazes (FONSECA, 2007), baseando-se numa suposição de que há uma estagnação do desenvolvimento em uma determinada faixa etária e reiterando a concepção do jovem e do adulto como uma criança (CARVALHO, 2006; MAFFEZOLI; GÓES, 2010; FERNANDES, 2011). Além disso, segundo Campos; Duarte (2011) e Fernandes (2011), as salas de recursos e o atendimento educacional especializado nem sempre são oferecidos a essa população. Segundo estas pesquisadoras, é comum a ausência da oferta do atendimento especializado para esta população.

Em relação às interações com os colegas, alguns pesquisadores afirmaram que nem sempre há qualidade e clareza nas relações que se estabelecem. Mantovani (2009), em seu trabalho sobre as contribuições da EJA para a construção da autonomia dos alunos com deficiência, descreveu a falta de tolerância e compreensão dos alunos para com os colegas com deficiência, o que a levou a promover um trabalho de sensibilização de todos os seus alunos com o uso de atividades e dinâmicas de grupo a fim de desmistificar paradigmas, concepções enviesadas e preconceitos sobre pessoas com deficiência. Fernandes (2011), em seus estudos e observações sobre as vivências docentes da EJA com a inclusão de jovens e adultos com deficiência, relatou que estes alunos mantinham poucas relações com os demais colegas da escola, pois até mesmo o espaço do recreio escolar não era utilizado para momentos de interação entre todos. Segundo a pesquisadora, estes alunos freqüentavam uma classe especial e passavam a maior parte do tempo na sala, fazendo com que os demais alunos da escola fossem até esta sala para vê-los.

Algumas pesquisas apontaram ainda a presença de familiares nas salas e a pressão que procuram exercer por resultados. Segundo as pesquisadoras, em algumas situações, tal pressão pode ocasionar o regresso do aluno da EJA regular comum para as salas de EJA das instituições privadas (FONSECA, 2007; CAMPOS; DUARTE, 2011).

Mediante estas perspectivas, torna-se imprescindível procurar dar vez e voz a estes sujeitos para que possamos conhecer e compreender a forma como percebem a escola e seu processo de escolarização, assim como vem sendo constituídas as suas participações nas vivências escolares. De acordo com Nunes et al (1998), ouvir o que o indivíduo com deficiência tem a dizer traz benefícios à produção de conhecimento, à transformação do atendimento oferecido, às relações entre os familiares e profissionais envolvidos. 
Para isso, buscar diferentes recursos e formas de expressão, fazendo uso das diferentes formas de linguagem, pode se apresentar como maneiras flexíveis de se relacionar com os sujeitos da pesquisa e com o objeto de estudo, oferecendo diferentes e interessantes maneiras de se expressar aos participantes.

Entre as diferentes formas de linguagem, o uso de fotografias tem crescido consideravelmente nas pesquisas sociais e tem sido apontado como uma construção e forma alternativa de pesquisa (MAURENTE; TITTONI, 2007) por possibilitar uma maior participação dos sujeitos no processo investigativo (MELLEIRO; GUALDA, 2005).

De acordo com Weller; Bassalo (2011), as imagens possuem uma dimensão extremamente democrática, pois são capazes de alcançar todos os grupos sociais e promover a expressão de sentimentos, identificação, lembranças, imaginação, visões de mundo, entre outros, mesmo quando as palavras não são capazes de atingi-los. Para as pesquisadoras, as imagens carregam signos e significados implícitos, trazendo um caráter mais abrangente de significação e permitindo a socialização dos significados.

Para Maurente; Tittoni (2007), a fotografia permite mostrar o que nem sempre pode ser facilmente descrito e pode dar visibilidade a aspectos que podem estar invisíveis até mesmo para os participantes da pesquisa. Além disso, o ato de fotografar permite aos indivíduos refletir sobre o objeto registrado (MANINI, 2002; MAURENTE; TITTONI, 2007; FIUZA; PARENTE, 2008), suscitando o ato de falar sobre o registro (ZAN, 2010).

Mediante estas prerrogativas, a presente pesquisa teve como objetivo descrever como os jovens e adultos com deficiência matriculados na EJA regular comum retratam a escola e percebem seu processo de escolarização por meio de registros fotográfico.

\section{MÉTODO}

Participaram desta pesquisa uma jovem adulta com 23 anos, estudante do $2^{\circ}$ ano do Ensino Médio de uma escola estadual, por ora denominada M; um aluno adulto com 42 anos, estudante de uma turma multisseriada de EJA de uma escola municipal, aqui identificado por D; e uma aluna adulta, 50 anos, também integrante de uma turma multisseriada de EJA de uma escola municipal, aqui denominada por R. Todos os participantes são deficientes intelectuais, porém apenas $\mathrm{M}$ possui diagnóstico médico e está inscrita como aluna com deficiência intelectual em seu sistema de ensino. 
Os participantes possuem baixo nível socioeconômico e são oriundos de dois municípios de pequeno porte do interior de São Paulo. Para a coleta de dados, foi solicitado aos participantes que fotografassem o ambiente escolar, destacando pontos que considerassem relevantes de serem comentados por eles.

Para os registros fotográficos foi utilizada uma máquina fotográfica digital pequena e de fácil manuseio da marca Sony, modelo Cyber-Shot, com 14.1 megapixels.

Os participantes tiveram três dias para realizar os registros fotográficos. Finalizados os registros, foram agendadas entrevistas individuais com os participantes acerca das imagens. Nesta entrevista, eles deveriam escolher apenas 10 fotografias entre todas registradas e informar à pesquisadora o motivo da escolha, fazer uma descrição da imagem, e apontar o motivo de sua relevância.

A entrevista deu-se nas dependências da própria escola, em sala reservada para esse fim, e foi gravada para posterior transcrição e análise dos dados. A análise dos dados foi mediante análise do conteúdo na modalidade categorial (BARDIN, 2010).

Todos os procedimentos metodológicos foram devidamente aprovados pelo Comitê de Ética em Pesquisas com Seres Humanos (CEP) sob o Parecer n. 139.146/2012.

\section{RESULTADOS}

A primeira fotografia escolhida pela participante $M$ apresentou uma imagem do banheiro dos professores (Figura 1). De acordo com ela, o registro e a escolha desta imagem devem-se à organização e ao cuidado com o banheiro de uso coletivo por parte dos professores, pois o tratamento dado ao banheiro dos alunos por eles próprios é bem diferente.

$M$ - Porque os professores são educados para usar o banheiro, e eles têm educação, não é igual às crianças que pegam e usam o banheiro e m... no chão. [...] Está em ordem o banheiro, está de outra opinião. [...]. (para uso dos alunos) tem bastante banheiro, só que tem uns que estão sem portas. Tem meninas lá que m... no chão.

Quando questionada sobre o comportamento destas meninas, M respondeu que "é pra fazer bagunça, fumar lá dentro, beber lá dentro, fumar e tudo". A participante reafirmou diversas vezes o seu descontentamento e sua indignação mediante as atitudes das demais alunas da escola em relação ao uso dos banheiros. 
D também abordou sua preocupação com os banheiros e sua conservação ao selecionar a fotografia das torneiras do bebedouro de água dos alunos (Figura 2). O participante comentou:

D - Uma coisa que eu não tirei foto... uma coisa... eu achei que não podia entrar em banheiro ... [...] Uma vez eu entrei ali e estava o cano quebrado... acho que agora arrumaram... está tudo tranqüilo...

Assim como M, D também manifestou sua preocupação com os espaços de uso coletivo.

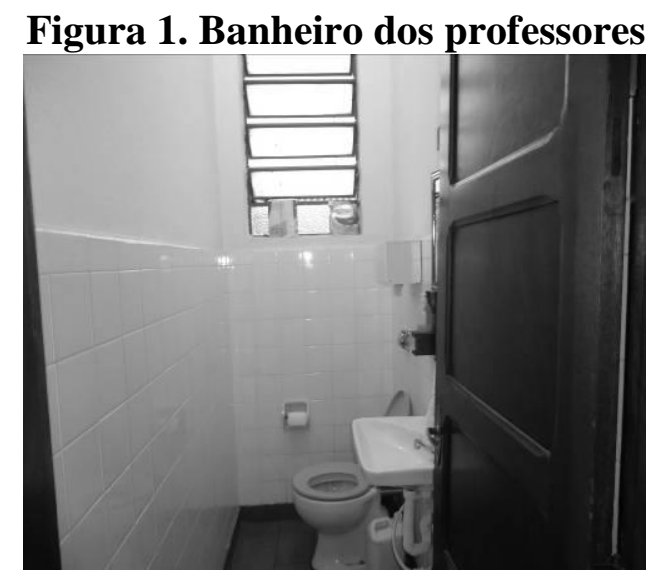

Fonte: Participante M.
Figura 2. Bebedouro dos alunos.

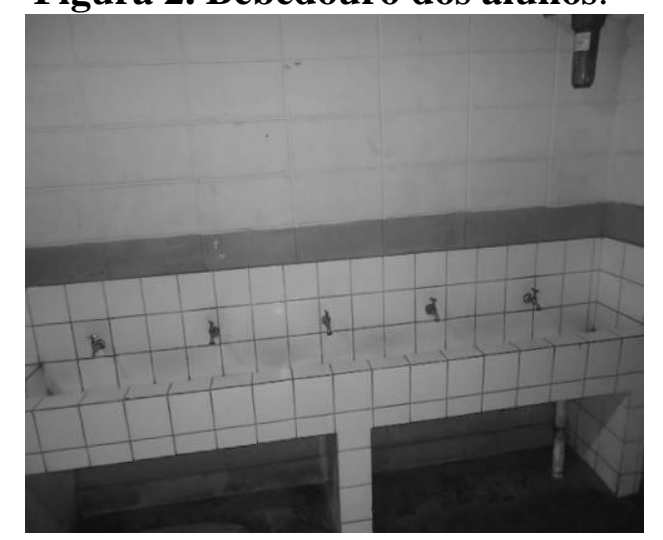

Fonte: Participante D.

A participante $\mathrm{M}$ selecionou como segunda imagem a fotografia da sala de informática (Figura 3). Segundo M, a fotografia desta sala era relevante "porque aí tem muitas coisas importantes para os alunos, os professores e também para os idosos que gostam de mexer para aprender muita coisa, matemática e outras coisas".

De acordo com os relatos de $\mathrm{M}$, a sala de informática era utilizada por professores e alunos com freqüência (duas vezes por semana) e havia autorização para uso da sala para a realização de trabalhos e pesquisas na internet. Para isso, havia professores que auxiliavam os alunos com mais dificuldade em utilizar os computadores.

M - Usa, pra assistir filme, pra assistir... não desenho, filme! Para mexer se precisar. Um dia, se me mandarem fazer algumas questões, eu vou lá e peço para o J. (diretor da escola) e o J. deixa. E no outro dia eu entrego para o professor. [...] Pode usar à vontade. E se você passar um texto para mim [...], você dá no livro (de registros de uso da sala de informática) o nome, e (pode) pesquisa dentro do computador. 
O participante D também mencionou a sala de informática ao comentar sobre a fotografia que tirou dos bancos infantis que ficam no pátio da escola, afirmando que eles estavam próximos da sala de informática (Figura 4).

Ao ser questionado sobre os usos da sala de informática, D relatou que "às vezes, ela (professora) punha ali no telão para a gente tirar alguma coisa... [...] E as vezes a gente brincava... algum joguinho..."

Como podemos observar, as salas de informática enquanto recurso para o aprendizado vem sendo disponibilizado aos participantes desta pesquisa conforme o nível de aprendizagem e a proposta de cada professor (a).

Quando questionada sobre a qualidade de sua aprendizagem mediante o uso do computador e as facilidades de acesso e uso da internet proporcionado pela escola, M. nos afirmou que

$M-A h$, ficou tudo na mesma [...], mas só que eu achei importante os professores explicarem para mim. Que é mais importante a língua dos professores do que o computador.

Para a participante, o uso dos recursos tecnológicos colabora no processo de ensino, mas os professores e sua atuação são fundamentais para o seu sucesso. Já o participante D não soube opinar.

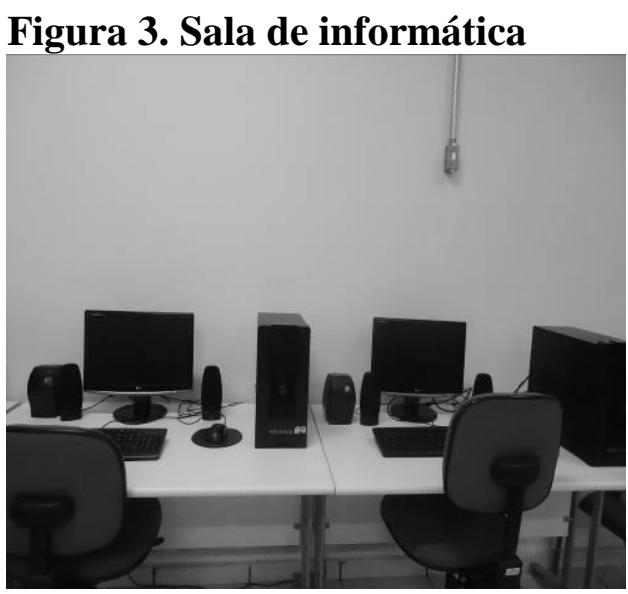

Fonte: Participante M.
Figura 4. Bancos infantis

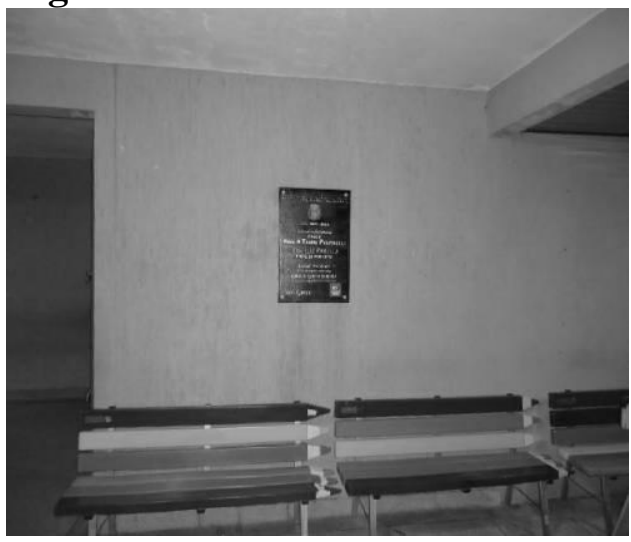

Fonte: Participante D.

A terceira fotografia escolhida retratou o pátio da escola (Figura 5). Ao comentar a imagem, a participante demonstrou grande afetividade em relação à escola. 
$M$ - Eu gosto muito desta foto. O primeiro dia que eu entrei aqui, dentro desta escola, eu chorei, eu falei assim: meu Deus, nunca vi uma escola bonita igual a essa. Eu estudei na (escola) C., eu estudei lá no (bairro) C., e gostei mais dessa.

A participante $\mathrm{R}$ também registrou o pátio externo da escola, demonstrando grande afetividade (Figura 6).

$R$ - Eu achei muito bonita, jardim também... tem as classes de aula!

$P^{3}$ - Você gosta da escola de verdade, hein?

$R-$ Gosto!

$P$ - Por quê?

$R$ - Porque aqui a gente aprende a ler, conhece os colegas, a professora...

Figura 5. Pátio externo.

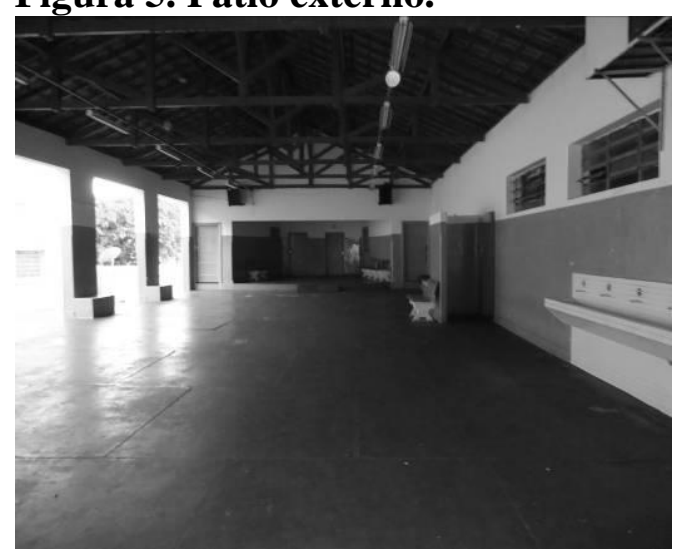

Fonte: Participante M.

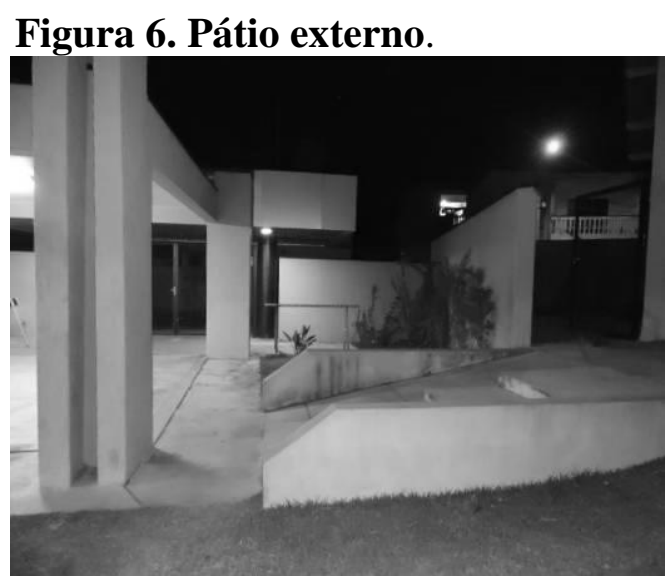

Fonte: Participante R.

$\mathrm{Na}$ escolha da quarta fotografia, $\mathrm{M}$ selecionou uma imagem na qual ela retratou uma lousa rabiscada e bastante danificada pelos alunos (Figura 7). M. novamente mostrou descontentamento com o comportamento dos demais colegas em relação à conservação do prédio da escola.

A preocupação com a conservação e a preservação do prédio da escola também foi constante nas falas dos participantes D e R.

D, ao comentar a fotografia que registrou o refeitório (Figura 8), apontou que sua escolha devia-se as lixeiras de coleta seletiva que ali estavam instaladas:

\footnotetext{
${ }^{3}$ Pesquisadora.
} 
D - Por causa desses negócios de por lixo... Não fica sujo, né? [...] Eu não como aqui... mas é bom ter isso aí, né? Para manter limpo, põe o papel...

$\mathrm{R}$ demonstrou sua preocupação ao fotografar uma sala de aula e comentar, entre outras coisas, que "tem gente que joga lixo no chão".

Figura 7. Lousa rabiscada.

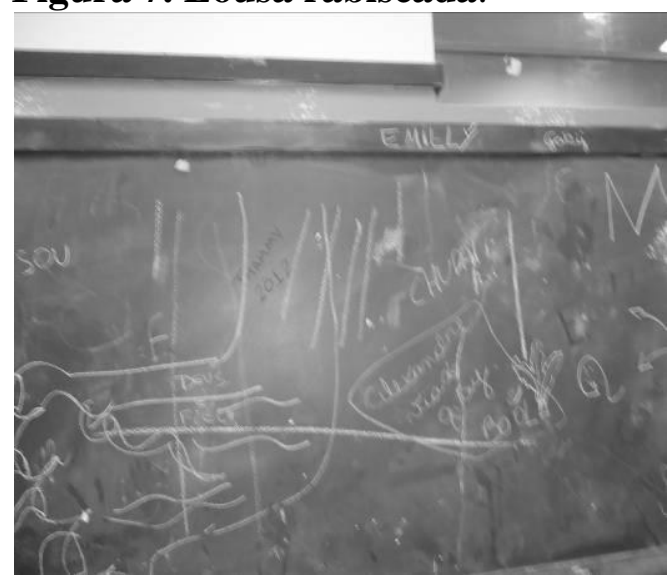

Fonte: Participante M.
Figura 8. Refeitório.

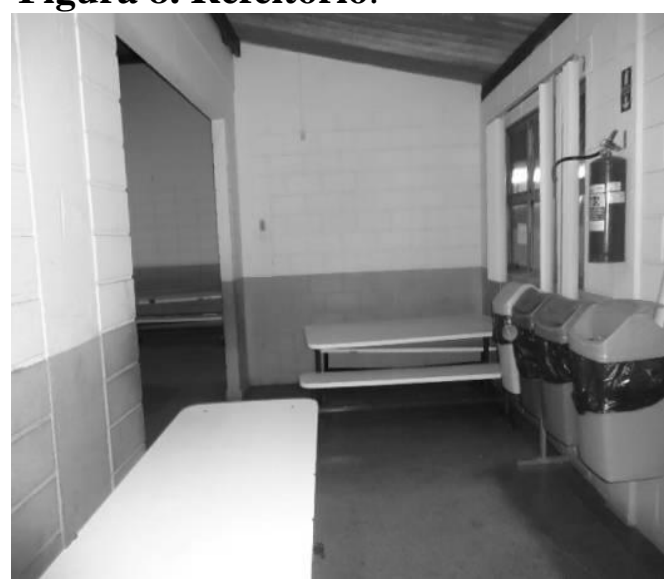

Fonte: Participante D.

A quinta imagem selecionada por $M$ trouxe uma fotografia de uma prateleira com diversos livros (Figura 9). Mais uma vez a participante retomou sua crítica ao descaso e mau uso dos recursos escolares pelos colegas, alegando que havia livros "que nem as professores conseguem ler" devido ao dano causado pelos alunos.

Quando questionada sobre o seu nível de compreensão acerca do conteúdo dos livros, $\mathrm{M}$ afirmou que

M-Entendo, e também tem aí muitos livros que eu gosto... português, que eu não sou muito chegada. Sou mais chegada em matemática, gosto muito mais de matemática [...] Português e inglês eu sou ruim, mas eu sou boa de matemática.

M. também descreveu o atendimento oferecido a ela pelos professores em virtude de sua condição de deficiente intelectual. Segundo a participante, a professora de História havia elogiado seu desempenho em uma avaliação dizendo "M., você está de parabéns. Depois que eu expliquei para você, você tirou 10.” As professoras de Filosofia e de Matemática também se esforçavam para garantir seu bom desempenho, segundo seu relato. De acordo com M., em uma determinada atividade, a professora de Filosofia lhe disse "primeiro eu vou escrever na 
lousa e depois eu falo para você”, e, em outra situação, a professora de matemática repetiu diversas vezes "a lição" para que ela compreendesse. Ainda segundo esta participante, o comportamento da professora de matemática a motivou significativamente, fazendo que desejasse cursar licenciatura na área e se tornar professora.

Mesmo diante deste quadro positivo, M. também afirmou que alguns professores agiam de forma bastante diferente. "Tem professor que deixa a gente fazer o que a gente quer", apontou. Além disso, também descreveu sua difícil relação com uma determinada professora que, segundo sua queixa, se recusava a explicar as atividades para ela. "Ela não traz nem um dicionário", afirmou.

Os participantes D e R também abordaram as ações pedagógicas e os materiais escolares utilizados por suas professoras.

$\mathrm{R}$, ao comentar a fotografia da sala dos professores, afirmou que a escolheu "porque tem os livros para aprender a ler, copiar as coisas do livro..." (Figura 10).

Quando questionada sobre a importância dos materiais, $\mathrm{R}$ afirmou que eram importantes "porque a gente usa a borracha para desmanchar o que está errado, a caneta para escrever...”. Sobre o trabalho da professora, R afirmou que

$R$ - Ela dá coisas boas, coisas bonitas... Ela quer que nós aprendamos, então ela faz força. É uma boa professora. [...] Ela tem paciência...

Desta forma, R também apontou os esforços e o compromisso da professora para com sua aprendizagem.

D também fotografou uma prateleira de livros e afirmou que "às vezes tem alguma coisa... [...] É, às vezes (ajuda) com alguma coisa." O participante não comentou sobre o trabalho de sua professora. 
Figura 9. Prateleira de livros.

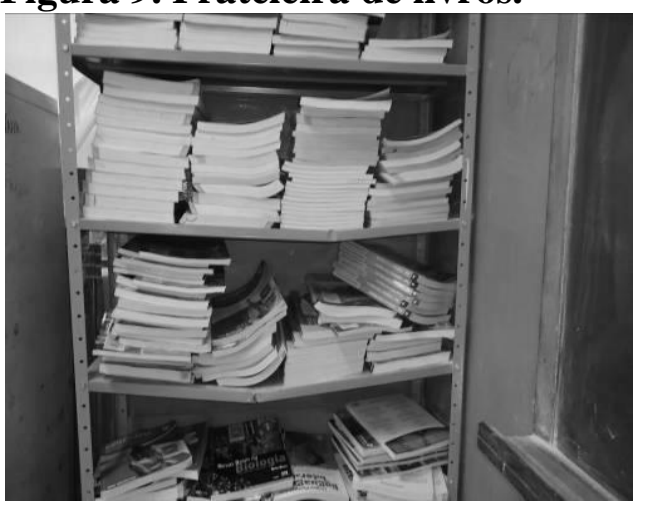

Fonte: Participante M.
Figura 10. Sala dos professores.

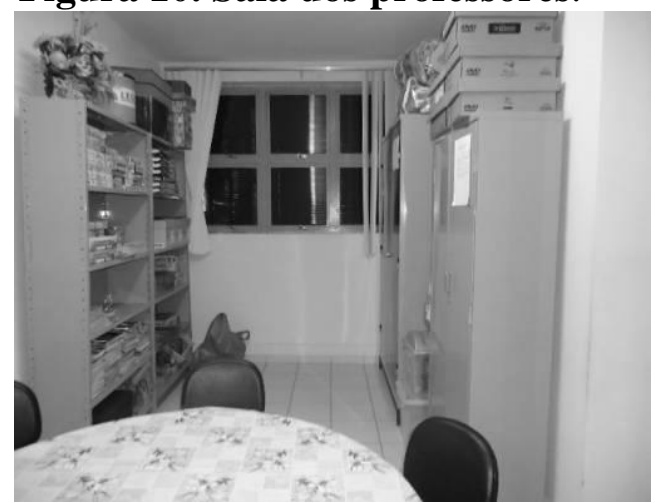

Fonte: Participante D.

A participante $M$ também selecionou a imagem de uma sala de aula e retomou seu discurso sobre o descaso dos colegas em relação ao uso do prédio e depredação dos recursos escolares (Figura 11). O mesmo discurso foi apresentado por $\mathrm{R}$ ao selecionar a imagem de uma sala de aula e afirmar que "é bonita a escola assim: limpinha, bem cuidada..." (Figura 12).

Figura 11. Sala de aula.

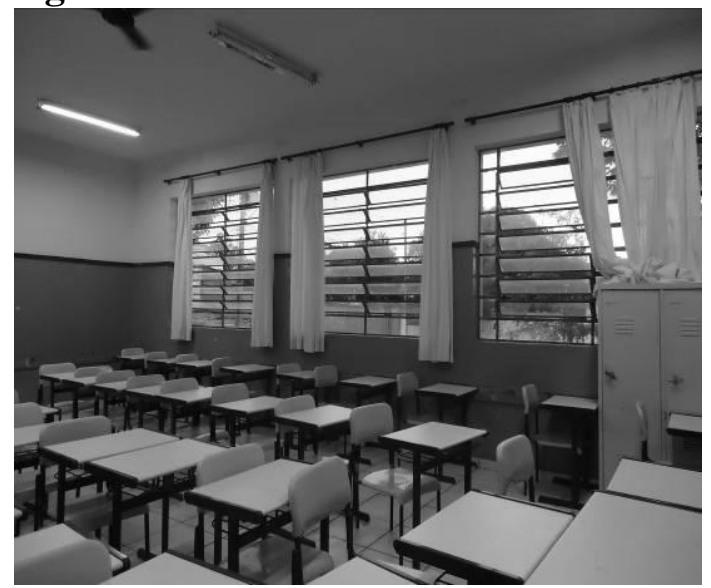

Fonte: Participante M.
Figura 12. Sala de aula.

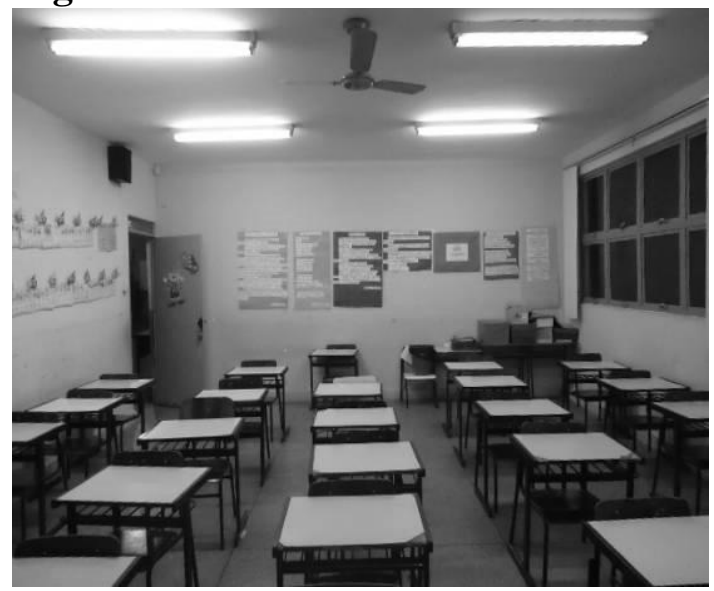

Fonte: Participante R.

As participantes $\mathrm{M}$ e R selecionaram imagens das salas das direções das respectivas escolas (Figuras 13 e 14). Quando questionada sobre a foto, $\mathrm{R}$ afirmou que se tratava da sala da diretora, e que “ela é educada, boazinha”. Já M fez um longo comentário sobre as ações do direto de sua escola acerca de seu acolhimento frente suas necessidades educativas especiais.

M - No dia em que eu entrei aqui, ele me falou M., você presta bem atenção nos professores porque você não vai ter só um, você vai ter doze professores e você tem que prestar muita atenção, porque você 
não é feia e nem burra. Você é inteligente [...]. No dia que eu entrei aqui, eu consegui aprender com ele.

Ainda sobre o diretor da instituição, M. afirmou que gostava muito dele "porque ele é o homem de capacidade pra fazer aquilo que ele está fazendo".

Figura 13. Sala da direção.

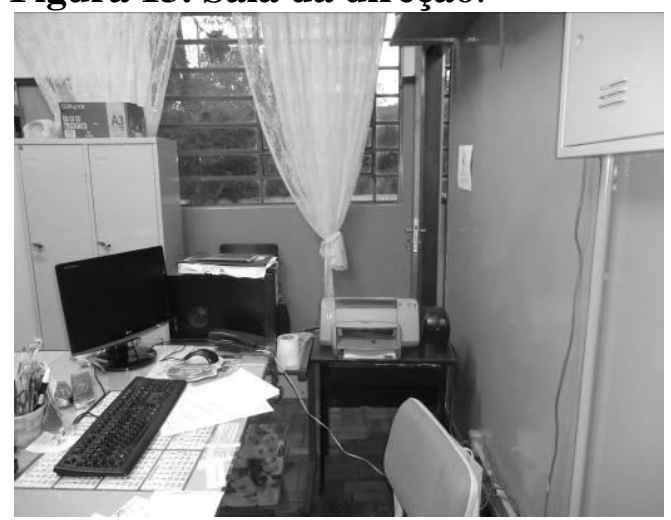

Fonte: Participante M.
Figura 14. Sala da direção.

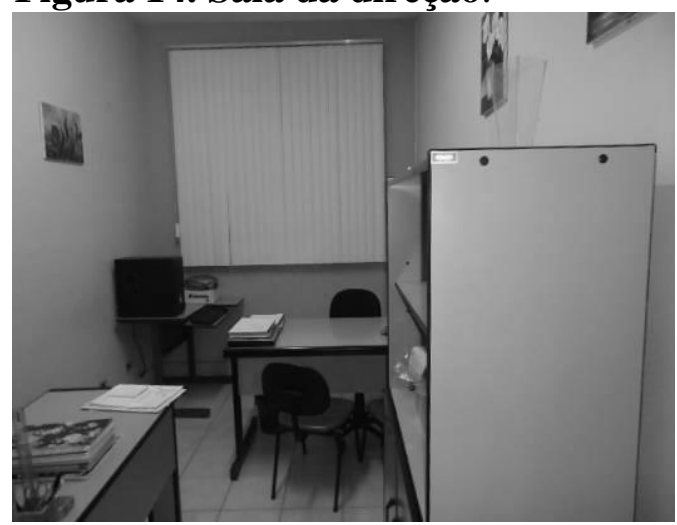

Fonte: Participante R.

A participante $M$ também selecionou a imagem da quadra da escola (Figura 15) e em seus comentários apontou que

$M-E u$ escolhi, eu tirei porque é muito importante a gente jogar vôlei, jogar futebol, os idosos também jogar futebol, o que eles quiserem. Também ali dá para a gente fazer ginástica.

Quando questionada pela pesquisadora se a prática de Educação Física seria importante aos alunos da EJA, M respondeu:

$M-A h$, importante! Eu gostaria de jogar vôlei, de fazer exercício na quadra porque eu tenho uma parte dessa perna que é quebrada. Essa perna e essa mão (lado esquerdo) não funcionam. Eu gostaria de ir para a quadra para fazer exercício para ver se eu consigo.

Os participantes D e R não fizeram nenhum comentário sobre alguma necessidade educativa que não estava sendo atendida ou em relação a alguma mudança que desejassem na ação pedagógica da professora ou na organização escolar. 


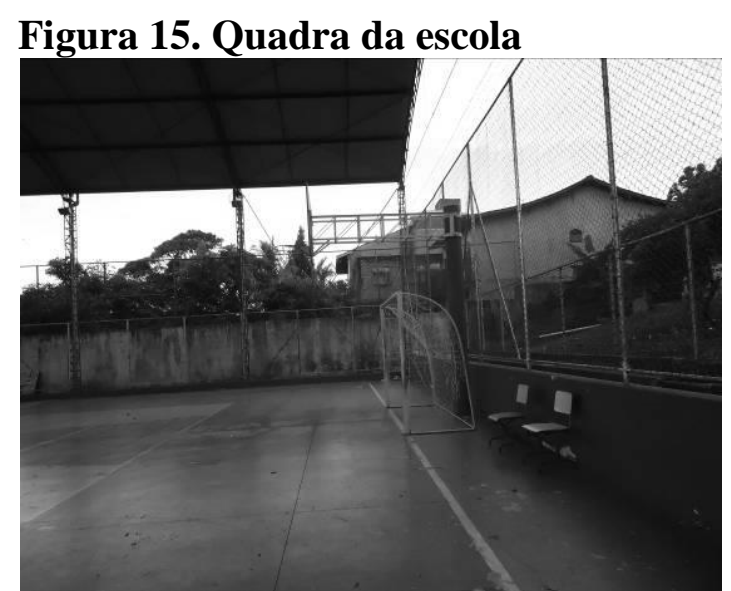

Fonte: Participante M.

\section{DISCUSSÃO}

A análise das falas dos participantes pode ser organizada em três categorias: Acolhimento, Relação professor e aluno, e Atendimento às necessidades educativas.

Em relação ao Acolhimento, todos os participantes demonstraram forte afetividade e sentimento pertencimento à escola e à EJA, principalmente $\mathrm{M}$ e $\mathrm{R}$ que atribuíram tais sentimentos à acolhida oferecida pelos diretores das escolas. Esses sentimentos se refletiram em suas preocupações com a preservação e conservação das escolas em contrapartida ao descaso e à depredação dos recursos escolares pelos demais colegas.

$\mathrm{O}$ acolhimento e o sentimento de pertencimento despertado pela EJA também foi destacado pelas participantes da pesquisa de Tinós (2010). Segundo a pesquisadora, as dificuldades de acolhimento do aluno com deficiência pela escola durante toda a sua trajetória pode ocorrer devido às dissonâncias entre a legislação vigente e as práticas inclusivas realizadas, pois a LDBEN n. 9.394/96 (BRASIL, 1996) responsabiliza os sistemas de ensino pelo oferecimento de currículos, métodos, técnicas, recursos educativos e organizações específicas para atender às necessidades e especificidades destes alunos; porém, o que tem ocorrido é a sua inserção nas salas de aula e o seu encaminhamento para os serviços de apoio - que são paralelos à escolarização e não transversais a ela.

Para Tinós (2010), o acolhimento e o sentimento de pertinência suscitados pela EJA devem-se à sua própria história de espaço de atendimento às minorias e seus históricos de fracasso escolar e/ ou falta de acesso à escolarização, apresentando um quadro de grande diversidade entre seus alunos. Além disso, os professores que atuam na EJA aprendem e 
compreendem que os alunos desta modalidade de ensino necessitam ser olhados e acolhidos de forma diferenciada devido às suas experiências de vida.

As participantes da pesquisa de Tinós (2010) encontraram também na EJA uma possibilidade para a inserção no mercado de trabalho, tanto pelo alcance de um nível de escolaridade que lhes permitiria o ingresso quanto pelo fato de serem tratadas de acordo com sua idade cronológica. Soma-se a estes fatos a questão da preocupação com o emprego e o mercado de trabalho, tão pertinente a esta faixa etária como nas posteriores.

O discurso dos participantes desta pesquisa corroborou as afirmativas de Tinós (2010), pois estes construíram seu sentimento de acolhimento e pertencimento a partir do diálogo motivador com a direção escolar, da diversidade encontrada na sala de aula (M. afirmou ter colegas idosos em sala de aula), e pelas possibilidades em realizar seus projetos de vida.

Sobre a relação professor e aluno, é fundamental considerar que as relações entre estes atores sociais dentro do processo de ensino e aprendizagem sempre se constituíram como um importante ponto de discussão acerca do desenvolvimento de práticas pedagógicas efetivas e, em se tratando de alunos com deficiência, tal temática apresenta-se ainda mais imprescindível.

O discurso de $\mathrm{M}$ apontou a importância da mediação oferecida pelos professores independentemente dos recursos disponíveis - enfatizando o quanto o diálogo e a ação pedagógica destes profissionais mediante os conteúdos propostos são cruciais para o desenvolvimento escolar dos alunos com deficiência. $\mathrm{R}$ também apontou a importância do comprometimento profissional ao afirmar que a professora "fazia força" e que tinha "paciência".

As pesquisas empreendidas por Maffezoli (2004), Tinós (2010) e Fernandes (2011) apontaram as diversas lacunas que podem ocorrer neste processo e comprometer o desenvolvimento escolar destes alunos.

Segundo Maffezoli (2004), para alguns alunos com deficiência intelectual, a experiência do aprendizado escolar pode ocorrer de maneira tão empobrecida que muitos não se recordam dela. Isso se dá devido à descrença nas habilidades e capacidades do indivíduo, fazendo com que as propostas e perspectivas de ensino sejam desenvolvidas de forma a abordar minimamente o conteúdo proposto para aquele nível de ensino. Assim, a abordagem pedagógica e a relação entre o professor e o aluno pautam-se numa visão reducionista e preconceituosa, não colaborando para a ampliação do repertório de conhecimentos destes alunos e não permitindo o seu pleno desenvolvimento. 
Já Tinós (2010), descreveu que os avanços alcançados pelas participantes de sua pesquisa deveram-se mais ao compromisso dos professores para com o aprendizado das mesmas do que devido aos recursos e propostas pedagógicas da EJA. Apesar da crítica da pesquisadora à falta de uma proposta pedagógica para a EJA que procure atender às suas demandas e diversidades, salientamos aqui o papel do professor mediante o compromisso com a aprendizagem do aluno e o seu desempenho para que este objetivo seja alcançado.

Fernandes (2011), ao abordar as relações entre professor e alunos, destacou que apenas uma boa relação não é o suficiente para garantir o sucesso no desenvolvimento escolar. Apesar do excelente entrosamento entre os participantes de sua pesquisa (uma professora e seus alunos de uma classe de EJA especial), a pesquisadora descreveu o uso de atividades descontextualizadas e infantilizadoras, aplicadas como um fim em si mesmo, e de maneira que os alunos dependessem demasiadamente da professora.

Mediante o exposto, podemos considerar que a relação professor-aluno de qualidade é aquela na qual há empatia entre os envolvidos, mas também há a proposição de situações pedagógicas que realmente ofereçam condição para o aprendizado do aluno, conferindo-lhe autonomia e independência em suas ações. E é neste aspecto que a qualidade da mediação oferecida apresenta-se como a peça fundamental do sucesso escolar de qualquer aluno, independente da presença de uma deficiência.

M., ao relatar a maneira como as atividades escolares lhes eram apresentadas, comentou a preocupação dos professores em ajudar-lhe a compreender a atividade que estava sendo aplicada a todos, ou seja, ela participava das mesmas atividades que eram propostas a todos os estudantes, e também a disponibilidade de uso da sala de informática para pesquisas e trabalhos escolares. D comentou o uso de joguinhos na sala de informática dentro de uma perspectiva positiva em relação às suas habilidades.

Portanto, os professores citados pelos participantes parecem atuar de conforma a promover o aprendizado destes alunos de uma maneira significativa e coerente com a perspectiva da educação inclusiva.

Em relação ao Atendimento às necessidades educativas, ao comentar a relevância da imagem da quadra (Figura 15), M. relatou a presença de uma sutil hemiparesia do lado esquerdo e sua crença de que a prática de atividades físicas na escola poderia colaborar no desenvolvimento e melhora dos movimentos do braço e da perna acometidos. 
A fala da participante apontou um aspecto de grande relevância e sempre abordado nas discussões acerca da educação inclusiva, mas nem sempre considerada na elaboração dos planos de ação e práticas pedagógicas: quais são as necessidades educacionais dos alunos e quais as suas perspectivas sobre a escola.

A Declaração Mundial de Educação para Todos (UNESCO, 1990) nos trouxe como primeiro objetivo a satisfação das necessidades básicas de aprendizagem de todos os alunos e a importância da atenção especial à educação das pessoas com deficiência, apontando para a necessidade de constante redefinição dos planos de ação em virtude da diversidade, da complexidade e do caráter mutável das necessidades educativas. Nestas perspectivas, os planos de educação e as ações pedagógicas devem voltar-se para as necessidades educacionais dos alunos e partir de seus desejos de realização. Isso implica em conhecê-los em profundidade, pois somente assim será possível traçar metas e objetivos cabíveis e alcançáveis.

A Declaração de Salamanca (BRASIL, 1994) afirmou a necessidade de se promover a alfabetização, o aprendizado da matemática e de habilidades básicas necessárias para jovens e adultos com deficiência em programas específicos de acordo com suas faixas etárias. A declaração também prescreveu a importância do currículo para tal e que o mesmo os auxilie na transição da escola para o mercado de trabalho.

Em atendimento aos pressupostos destas declarações, as legislações brasileiras também indicaram os mecanismos para o atendimento educacional dentro da perspectiva da satisfação das necessidades básicas.

A atual LDBEN n. 9.394/96 (BRASIL, 1996), que dedicou um capítulo à Educação Especial, abordou a responsabilidade dos sistemas de ensino e das escolas no processo de organização para o oferecimento de um atendimento que satisfaça as necessidades educativas dos alunos com deficiência. Nesta mesma legislação, a Seção V - que trata da Educação de Jovens e Adultos - em conjunto com o Capítulo V - da Educação Especial - abordou a responsabilidade e a necessidade da construção de um sistema de atendimento por parte do Poder Público que realmente vá ao encontro das perspectivas desta população específica de alunos quando estes ingressam na escola.

A intersecção entre a EJA e a Educação Especial, dessa forma, permite o desenvolvimento de planos e projetos de trabalho flexíveis que acomodem o desenvolvimento destes alunos de forma a ampliar as oportunidades de escolarização, formando-os para o mercado de trabalho e garantindo-lhes sua efetiva participação social (BRASIL, 2008). 
Tinós (2010) também relatou a ausência do atendimento adequado às necessidades especiais das participantes de sua pesquisa durante suas trajetórias escolares. Uma das participantes, deficiente física que necessitava utilizar um computador para poder registrar o conteúdo das aulas, não conseguiu acesso ao equipamento, pois de acordo com a direção escolar, só havia um na escola e era de uso da coordenação. A mãe da outra aluna participante, uma jovem deficiente intelectual, questionou as atitudes de uma determinada escola na qual sua filha foi matriculada alegando que a instituição se apresentava como inclusiva e que não desenvolvia situações didático-pedagógicas que justificassem tal apresentação.

$\mathrm{O}$ atendimento às necessidades especiais de todos os alunos é previsto e prescrito na legislação brasileira, mas muitas escolas têm apenas inserido os alunos, deixando de atender as suas perspectivas de escolarização e dificultando seu desenvolvimento escolar e social.

\section{CONSIDERAÇÕES FINAIS}

Os participantes desta pesquisa mostraram-se bastante satisfeitos com sua escolarização, demonstrando um forte sentimento de acolhimento e de pertencimento à EJA manifestados na escolha cuidadosa das imagens e em sua preocupação constante com os cuidados necessários para manutenção do prédio escolar.

O acolhimento dos alunos pela escola é fundamental para que eles se sintam motivados em sua trajetória escolar e, em se tratando de alunos jovens e adultos com deficiência, cujas trajetórias podem carregar histórias de insucessos, fracassos e abandonos escolares, a forma como estes são recebidos pela escola pode ser fundamental para a sua motivação e bom desempenho escolar.

Eles também apontaram que as relações entre professores e alunos com deficiência se encontram em processo de desenvolvimento e constituição de crenças e valores. Conforme nos apontou M, apesar da boa receptividade e atenção que recebe dos professores, a participante ainda encontrou barreiras em relação a alguns profisssionais. Isso nos apontou que a descrença na capacidade e nas habilidades dos sujeitos com deficiência ainda permeia a concepção que alguns professores envolvidos na educação de jovens e adultos com deficiência na EJA possuem acerca desta população específica. E, por conseguinte, tal concepção reflete-se na disponibilização e no acesso aos recursos necessários para atender às 
necessidades especiais destes alunos, assim como na própria relação que se estabelece entre o aluno e o professor dentro da sala de aula.

O desmantelamento destas concepções negativas requer tempo e experiência na atuação junto a esta população de alunos, aliados à formação continuada e ao desejo de conhecê-los melhor para poder atender às necessidades e aos desejos desta população escolar específica.

\section{REFERÊNCIAS}

BARDIN, L. Análise de conteúdo. 4. ed. Lisboa: Edições 70, 2010.

BRASIL. Presidência da República. Lei n.9394 de 20 de dezembro de 1996. Estabelece as Diretrizes e Bases da Educação Nacional. Diário Oficial da União, Brasília, 20 de dezembro de 1996. Disponível em: <http://www.planalto.gov.br/ccivil_03/LEIS/19394.htm>. Acesso em 14 abr.2012.

Presidência da República, Secretaria Especial dos Direitos Humanos. Declaração de Salamanca e linha de ação sobre as necessidades educativas especiais. Brasília, DF: Coordenadoria Nacional para Integração da Pessoa Portadora de Deficiência - CORDE, 1994.

Ministério da Educação. Secretaria de Educação Especial. Política Nacional de Educação Especial na Perspectiva da Educação Inclusiva. Brasília, MEC/SEESP, 2008. Disponível em: <http://portal.mec.gov.br/arquivos/pdf/politicaeducespecial.pdf>. Acesso em: 14 abr. 2012.

CAMPOS, J. A. de P. P.; DUARTE, M. O aluno com deficiência na EJA: reflexões sobre o atendimento educacional especializado a partir do relato de uma professora da educação especial. Revista de Educação Especial de Santa Maria, v. 24, n. 40, p. 271-284, 2011.

CARVALHO, M de F. A relação do sujeito com o conhecimento: condições de possibilidades no enfrentamento da deficiência mental. 2004. 196f. Tese (Doutorado em Educação). Faculdade de Educação. Universidade Estadual de Campinas, Campinas, 2004.

FERNANDES, A. P. C. dos S. Estudos e observações sobre vivências docentes da Educação de Jovens e Adultos no processo de inclusão escolar. 2011. 145f. Dissertação (Mestrado em Educação). Centro de Ciências Sociais e da Educação, Universidade do Estado do Pará, Belém, 2011.

FERREIRA, W. B. EJA \& Deficiência: estudo da oferta da modalidade EJA para estudantes com deficiência. In: AGUIAR, M. A. da S. (org.) Educação de Jovens e Adultos: o que dizem as pesquisas. Recife: UFPE - MEC/SECAD, 2009. Disponível em:

<http://www.ufpe.br/cead/eja/textos/dizem_as_pesquisas_1.pdf>. Acesso em: 02 maioi 2012.

FIUZA, B. C.; PARENTE, C. O conceito de ensaio fotográfico. Discursos Fotográficos, v. 4, n. 4, p. 161-176, 2008. 
FONSECA, M. V. A. T. Educação de jovens e adultos e educação especial: versões e inserções. Disponível em

http://www.cereja.org.br/arquivos_upload/mirella_fonseca_eja_educ_espec.pdf . Acesso em 12.04.2012.

GONÇALVES, T. G. G. L. Escolarização de alunos com deficiência na Educação de Jovens e Adultos: uma análise dos indicadores educacionais brasileiros. 2012. 72f. Dissertação (Mestrado em Educação). Centro de Educação, Comunicação e Artes, Universidade Estadual de Londrina, Londrina, 2012.

MAFFEZOLI, R. R. “Olha, eu já cresci”: a infantilização de jovens e adultos com deficiência mental. 2004. 158f. Dissertação (Mestrado em Educação). Faculdades de Ciências Humanas. Programa de Pós-Graduação. Universidade Metodista de Piracicaba, Piracicaba, 2004.

MAFFEZOLI, R. R.; GÓES, M. C. de. Jovens e adultos com deficiência mental: seus dizeres sobre o cenário cotidiano de suas relações pessoais e atividades. Trabalho apresentado na $27^{\mathrm{a}}$. Reunião da ANPED. Disponível em: <http://.anped.org.br/reunioes/27ra /programacao _gts/programacao do gt15>. Acesso em: 02 maio 2012.

MANINI, M. P. Análise documentária de fotografias: um referencial de leitura de imagens fotografias para fins documentários. 2002. 231f. Tese (Doutorado em Ciências da Comunicação). Departamento de Biblioteconomia e Documentação da Escola de Comunicações e Artes da Universidade de São Paulo, São Paulo, 2002.

MANTOVANI, J. As contribuições da Educação de Jovens e Adultos na construção da autonomia dos alunos deficientes. Campinas, Universidade Estadual de Campinas, Faculdade de Educação, 2009. 33f. Trabalho de Conclusão de Curso.

MAURENTE, V.; TITTONI, J. Imagens como estratégia metodológica em pesquisa: a fotocomposição e outros caminhos possíveis. Revista Psicologia e Sociedade, n. 19, v. 3, p. 33-38, 2007.

MELLEIRO, M. M.; GUALDA, D. M. R. Explorando a "fotovoz" em um estudo etnográfico: uma estratégia de coleta de dados. Revista Brasileira de Enfermagem, n. 58, v. 2, p. 191-193, mar/abr 2005.

NUNES, L. R. D. de P. et al. Questões atuais em Educação Especial: pesquisa em educação especial na pós-graduação. Rio de Janeiro: Sette Letras, 1998.

SÃO PAULO. Secretaria dos Direitos da Pessoa com Deficiência. Relatório Mundial sobre a deficiência. São Paulo: SEDPcD, 2012.

SIEMS, M. E. R. Educação de jovens e adultos com deficiência: saberes e caminhos em construção. Educação em foco, Juiz de Fora, v. 16, n. 2, p. 61-79, fev 2012. Disponível em <http://www.ufjf.br/revistaedufoco/files/2012/08/Texton-031.pdf>. Acesso em: 10 nov. 2014. 
TINÓS, L. M. S. Caminhos de alunos com deficiências à Educação de Jovens e Adultos: conhecendo e compreendendo trajetórias escolares. 2010. 125f. Tese (Doutorado em Educação Especial). Centro de Educação e Ciências Humanas. Programa de Pós-Graduação em Educação Especial. Universidade Federal de São Carlos, São Carlos, 2010.

UNESCO. Declaração Mundial sobre Educação para Todos: satisfação das necessidades básicas de aprendizagem. Disponível em <http://unesdoc.unesco.org/images/0008/000862/086291por.pdf>. Acesso em: 10 maio 2012.

WELLER, W.; BASSALO, L. de M. B. Imagens: documentos de visões de mundo. Sociologias, Porto Alegre, ano 13, n. 28, p. 284-314, set/dez 2011.

ZAN, D. D. P. Fotografia, currículo e cotidiano escolar. Pró-posições, Campinas, v. 21, n. 1, p. 149-161, jan/abr 2010. 